\title{
THE VULNERABILITY AND LIVELIHOOD STRATEGIES OF URBAN REDEVELOPMENT-INDUCED RELOCATEES IN ADDIS ABABA: THE CASE OF PEOPLE RELOCATED FROM ARADA-SUBCITY TO NIFAS SILK LAFTO-SUBCITY
}

\author{
Habtamu Atlaw \\ Jigjiga University, College of Social Science \& Humanities, Ethiopia \\ hagiju2000@gmail.com
}

\begin{abstract}
The study aimed to investigate the vulnerability and livelihood strategies of urban relocatees. The study used purely qualitative research methodology. Semi-structured interview, key informant interview, focus group discussion and observation were employed to generate primary data. Relocating people from inner city slum to the outskirt has left relocatees vulnerable to weak social network. However, it has led relocatees turn out to be free of exclusion. Relocation has enabled relocated people to live in neat and better planned environment. It, however, exposed relocatees to unaffordable urban monetized life. Relocatees employed various strategies to cope up with the relocation- induced stun, such as, changing consumption pattern, reducing expenditure, using second hand product and increasing the quantity of labor in household. Though such strategies have contributed to maintain relocatees 'livelihood, they also increase vulnerability and impoverishment instantly or in the long run.
\end{abstract}

\section{Indexing terms/Keywords}

Vulnerability; Livelihood Strategies; Urban Relocatees and Inner City Slum

\section{Academic Discipline and Sub-Disciplines}

Development Science

\section{SUBJECT CLASSIFICATION}

Social Sciences

\section{TYPE (METHOD/APPROACH)}

Qualitative Study: Interview, FGD, Observation, Content Analysis

\section{Council for Innovative Research}

Peer Review Research Publishing System

Journal: Journal of Social Sciences Research

Vol. 6, No. 2

Jssreditor.cir@gmail.com

www.jssronline.com 


\section{INTRODUCTION}

Most of residents of Africa's cities live in slums. In other words, about 72 percent of the urban populations of Africa live in slums (Cohen 2005). Moreover, the condition needs serious attention in Sub Saharan Africa where urbanization has become virtually synonymous with slum growth in one hand (UNFPA, 2007) and slum population almost doubled in 15 years, reaching nearly 200 million in 2005 , on the other hand (Sommers, 2010).

Like many other urban residents of Africa, about 70 percent of the urban populations of Ethiopia reside in slum. The condition can be dire in the capital city, Addis Ababa, where slums constitute the greater portion of the residential areas. Various literatures indicate that more than $80 \%$ of the city's population lives in slums (UN-Habitat, 2004; Yonoineshet, 2007; Elias, 2008; Gebre, 2008) that are characterized by overcrowded neighborhoods with no or little basic infrastructure and municipal services, poor hygienic conditions, lacking safe drinking water and sewage, absence of tenure security, high rate of HIV/AIDS, high rate of unemployment and informal economy.

Therefore, high incidence of water borne diseases, poverty, vulnerability to sexual and physical assault, weak social ties with the outsiders and high burden on young girls who are also responsible to collect water from distant are evident in the inner-city slums. On the other hand, accessible urban services, such as health, education, transport, source of income, self-help institutions and strong social ties could be identified as desirable traits in the inner part of Addis Ababa's slums. Therefore, it is erroneous to understand slums merely from the point of views of its objectionable facet.

Since 1960s, various intervention approaches have been undertaken to renew slums in Addis Ababa city. In keeping with the thinking of the times, the first meaningful policy measure that the Ethiopian government took in the 1960s to address the problems posed by slums in the inner areas of Addis Ababa was relocation (UN-Habitat, 2007). Relocation is also currently being implemented despite its failure to find sustainable development. In general, in spite of some five decades of intervention by government and various NGOs, the efforts were ineffective to achieve sustainable urban development. This is because of the fact that the multifaceted nature of slum is seldom considered in the strategies adopted by most slum improvement programmes (Habtamu, 2014).

Urban relocation in Addis Ababa has been a subject studied for the last few years. In fact, in Ethiopia, urban relocation has been under-researched (Gebre, 2008). The available studies have also focused on assessing the socio-economic impacts of relocation on relocated people. Thus, the studies (Berhanu, 2006; Gebre, 2008; Biruk, 2009) found out that relocation has adverse impact on relocatees' social and economic assets.

Apart from this, the relocated people face a set of source of vulnerability. Westley and Michael (2002) argue that people without social network tend to be more vulnerable than those who were part of network. In response to this, they designed livelihood strategies to build asset bases and access to goods and services (Ephrem, 1998). Livelihood outcomes may, however, lead into either virtuous or vicious cycles.

The studies undertaken on urban relocation have not fully understood how relocated people are vulnerable to urban economy, environment and social context. In addition to this, the studies did not consider the strategies employed by relocated people against the adverse impacts of relocation. As a result, relocated people are often regarded merely as passive victims. In general, the currently available data are inadequate for clarifying the most critical issues concerning the effects of residential relocation upon the subject population.

Therefore, this paper primarily intends to assess the vulnerability and livelihood strategies of relocated people in Addis Ababa with the particular reference to those people who were moved from inner city (Arat Kilo) to another area. Specifically, the study is intended to achieve various objectives such as, assessing how relocated people are vulnerable to urban economy, environment and social context, strategies developed by relocated people and outcomes of such strategies. To this end, it is expected that the lessons learned from this paper can be utilized to increase effectiveness of planning and decisions of slum improvement projects in other areas.

\section{STUDY AREA}

The city of Addis Ababa is located almost in the center of Ethiopia. Astronomically, the city lies between $80^{\circ} 55^{\prime} \& 90{ }^{\circ}$ $05^{\prime}$ North latitude, and $38^{\circ} 40^{\prime} \& 38^{\circ} 50^{\prime}$ East longitudes. The city is only 129 years old. The city population is thought to be more than four million, and increasing at a rate of $8 \%$ per annum (Mathewos, 2005). In 1999, surprisingly, 46.9\% of city populations were migrants (CSA, 1998).

Poverty is one of the many challenges facing city. According to UN-Habitat (2007), about 70 to $80 \%$ of the Addis Ababa's populations are living at or below subsistence level. The intensity of poverty varies across different sub-cities of Addis Ababa. Poverty is much more pronounced in the inner and/or oldest parts of the city (Netsanent 2009). Particularly, Arat Kilo area is hard hit by poverty. Available data indicate that more than 80 percent of Addis Ababa's population lives in slum areas. This could imply that most of the sub-cities have a substantial proportion of households bereft of any one of the internationally accepted five key slum indicators. Currently, the city contains ten sub-cities and 116 weredas. The studied communities were relocated from Arada sub-city, Arat Kilo area (inner part of city) to Nifas Silk sub-city: Gofa Camp, Lafto and Jamo sites. I deliberately selected Nifas Silk Lafto sub-city because more than half of relocation affected people of Arat Kilo were moved to this location. 


\section{METHODOLOGY}

Since qualitative approach enables to understand the phenomenon in depth, it was employed in this study. People from different part of the city were moved to Nifas Silk Lafto Sub-city. This study focused on those relocatees who have been relocated from Arad Sub-city, specifically Arat Kilo area, to Nifas Silk Lafto. Therefore, to get the target group, snowball sampling was employed. The data were, therefore, generated using semi-structured interview, key informant interview, focus group discussion and observation. Semi-structured interview was continually managed till maximum of data that is often marked by resemblance of information had been found, and thus, 39 relocatees were interviewed.

I did not able to implement focus group discussion for the entire study communities, because, it was difficult to bring people together at one particular site. I, therefore, used focus group discussion at Jamo 1 where relocatees relatively live close to each other's, and have accepted the request. The discussion contained 9 people representing various groups, such as, women headed household, and male headed household and children. The Kebele and sub-city authorities of the new and old locations were taken as key informants to generate further and unique data .Thus, six Kebele and two Subcity authorities were met to generate in depth information. Observation was also employed to ascertain the information given by informants during interview about physical capital and environmental context of the new place of residence.

Then, the collected data were analysed after they were categorised into different themes based on their characteristics. To make further analysis and interpretation, the categories were again disintegrated to phenomenon. Some meaningful responses have been placed in the analysis as quotes.

\section{CONCEPTUAL FRAMEWORK}

Vulnerability can broadly be grouped into sources of vulnerability accruing to the social context of cities, the nature of the urban economy and the urban environment (Rakodi, 2002; Farringtan et al, 2002). There are substantial differences between urban and rural environment, differences in vulnerability context-urban resident is more vulnerable to urban economy, social and environmental context (Farrington et al, 2002), than the counterpart. The majority of urban dwellers of developing countries reside in slum area that is characterized by socio-economic and environmental problems. The study by Sufaira (2013) revealed that slums dwellers are characterized by poor socio-economic status with poor physical environment- with non-existent solid waste disposal system. The major contributors to poor environment in slum are excreta and solid waste. People living in slum are exposed to ill health from poor environment (Habtamu, 2014). On the other side, slum areas are also known for their atmosphere of fear and violence (Bloom et. al, 2008).

The vulnerability to urban social, economic and environmental context is, therefore, pronounced in slum areas where vast majority of people are poor. Thus, over the past five decades, governments in developing region have adopted various strategies to tackle slum problems. One of the predominant strategies has been slum resettlement or relocation, which is also still being implemented in many of developing countries. This study aimed to assess how relocatees are vulnerable to the existing urban contexts, and also strategies developed by these people- including outcomes of strategies.

\section{FINDINGS AND DISCUSSIONS}

\subsection{Relocatees and Urban Context}

\subsubsection{Relocation and Urban Social Context}

Cultural diversity, social fragmentation and income inequality are typical facts in urban areas than the counterpart (Farringtan et al, 2002). As a result, building up and maintaining social network and inter-household mechanism of trust and collaboration is considered difficult in cities. However, this is not necessarily true everywhere. The studied community lived for many years in the previous location. This led them to prevail over diversity and establish strong social network and collaboration. The trend used to be manifested by various scenarios. In the previous areas, people with different ethnic and religious background affiliated to the same iddir (burial) institutions. In addition, they used to visit each other when one gets sick and at a time of death. However, social disintegration and diversity are the prominent consequences of relocation arising in the new location. Weak social network and less collaboration are, therefore, problems that relocated people face in the new place of residence. The finding is therefore consistent with Moser (1998) argument: the movement of people in response to urban development creates social disintegration.

On the other side, inhabitants used to have a weak social relation with other community, who live outside of slum area. According to informants, the former place of residence, Arat Kilo, was perceived by outsiders as a place of crime, disturbance, drug, drunkard and prostitute. Outsiders used to stigmatize those people living in this area. They had pervasively seen dwellers of this area as delinquent and violent. Therefore, the dwellers had been socially excluded and no likelihood to share livelihood experiences of others. In the new settlement, however, relocatees are joyful being they are free of stigmatization and have opportunity to integrate with different people and share their livelihood experiences.

Informants stated that children were particularly at risk of marginalization in the previous location. In any case, outsiders had not allowed their children to intimate with children of Arat kilo because they used to perceive them as thieve, violent and drug addicts. In addition, children of this area were abused verbally by passerby or other outsiders- when they played on the pavement or went to school or somewhere outside the living environment. The phenomena, however, remained there in the previous location. "In the new location, no one still insulted me like the previous one", I heard from young children during focus group discussion. 


\subsubsection{Relocation and Urban Economic Context}

Cash oriented life is more likely attributable to urban area than rural area. Urban inhabitants must buy basic necessities such as food, water, fuel wood and kerosene, and they have to pay more for education, health, transport and others than the rural population. Thus, urban residents need more cash income. In fact, majority of urban residents of developing countries are not in a condition to manage their basic necessities. They could not also afford for large quantity of commodities and other services as they are mostly generating meager income. Moreover, relocated people are quite vulnerable to urban economic context than non-relocatees. This is because of that relocation has adversely affected their livelihood activities and assets (Gebre, 2008; Habtamu, 2014).

In other words, people dislocated from inner cities are likely to lose important locational advantages (Gebre, 2008). Multitudes of formal and informal income generating activities are available for the inner city slums (UNCHS, 1991). Moreover, lose of long established social bond which has a considerable role in building and protecting peoples' livelihood could make relocatees more vulnerable to the phenomenon. A livelihood assessment conducted by Westley and Michael (2002) found out that people without social network tended to be more vulnerable than those who were part of network.

In the previous location, relocated people used to manage to pay for frequent smaller quantity purchase as they were generating meager income. "You can buy even one heads of onion in Arat Kilo, but here you cannot do that", one informant said. On the other side, the study found out that commodities are relatively expensive in the new location than the previous one. This is mainly due to that retailers often provide quality and big size products which can be afforded by middle income and rich section of the population, while it is beyond the paying capacity of relocatees whose livelihood activity and assets are debilitated. The vulnerability of relocatees to the urban commercialization life is worsened due to the drastic increases in food prices. As a result of lack of retail services, accessible source of income and loss of the long established social network, relocated people are more vulnerable to food price rise.

\subsubsection{Relocation and Urban Environmental Context}

Previously, relocated people had been living in an area that is attributable to poor quality. Lack of clean water, insufficient drainage, poor sanitation, air pollution resulting from fuel wood smoke, stove and old motor vehicles, and noise pollution resulting from motor vehicles, over lauded music and drunkard were a typical problem relocated people were facing prior to relocation. Such poor environmental traits led a number of people to ill-health. Relocated people are more likely having relief in the new location, given relatively worth living environment. This makes them to be less susceptible to disease resulting from poor quality environment.

Due to shortage of toilet, there were people, particularly, children and drunkard, excreted in front of or nearby housing, and thus has worsened the quality of living environment. The current living environment is, however, situated free of human excreta as people have access to adequate toilet. Previously, people used to live in congested area suffering from poor lit and narrow street. As a result, women and children frightened to go out at night. The absence of vacant land and open spaces were attributable to the previous location. Therefore, children had no access to open space for play. They were vulnerable to broken glass, excreta, and car accident at play environ. Relocated people including children have, however, found it the new location well-planned with adequate open space which is not occupied by harmful things, and thus safe for children to play. In the previous location, I could not easily go to neighbours home especially that is situated at the back of my home- but here I am free to go everywhere, one informant mentioned.

\subsection{ADAPTIVE AND COPING STRATEGIES OF RELOCATEES}

The relocatees employed adaptive and coping livelihood strategies against the adverse impacts of relocation. According to farringtan et al (2002), adaptive strategy designed to improve circumstances in long term, while coping strategy designed to respond to shocks in the short term. Therefore, international and domestic migration is of adaptive strategies carried out by relocatees in their attempt to stabilize their livelihood. Some relocatees have sent their young children abroad especially to the Middle East, whereas others have sent their children, who are on early young stages, to their better off relatives. Some relocatees have developed strategy relating to birth: spacing and ceasing fertility. Increasing the quantity of labor in household was also action taken by them to manage the changes in their livelihood circumstances. Children after school or dropping out of their school have engaged in various income earning activities. Changing consumption pattern: reducing mealtime, food quality and quantity has been one of the strategies developed by relocated people. Expenditure reduction: using second hand products (e.g. clothes and shoes) than ever before and walking rather than catching bus, could be identified as a case in point.

\subsection{OUTCOMES OF STRATEGIES}

The livelihood strategies that people employed to recover from the adverse impacts of any shock or promote their livelihood may increase vulnerability immediately or in long run (Moser, 1998). In this study, the outcomes of the livelihood strategies are categorized into desirable and undesirable. Thus, households' income enhancement and expenditure reduction could be considered as a desirable outcome. The phenomenon, however, may have unforeseen negative livelihood consequences. Changing consumption pattern has adverse health effects. It makes people, particularly children, easily vulnerable to disease because of lower resistance. For instance, literatures shows that child malnutrition had increased (Jespersen, 1990) and infant mortality rates were rising, and life expectance was falling (Potts, 1997) in urban Zambia in 1990s due to inadequate quality and quantity food consumption. Similarly, in Addis Ababa, one study showed that the occurrences of weight loss, illness and declines in educational and work performance in families exposed to food 
shortages (Yared, 2010). Walking to work or somewhere else reduces people's productive capacity and their effective working days. On the other side, those reliant on walking waste productive time on travel (Brown \& Lloyd-Jones, 2002).

Migration improves the livelihood condition of migrants, including their family. However, it is not uncommon to see the negative livelihood implication of migration. Those children who have been sent to their relatives have rarely found emotional support. Ansell (2005) argue that children separated from their families are exposed to lack of emotional support, love, care and sense of belongingness because these needs are more difficult to meet in relatives than in a family environment. On the other side, sending women in Middle East can result in poor social and health effects. According to Esim and Smith (2004) migrants face physical, psychological and verbal abuses. Clearly, Gamburd (2002) argue that "migrants in the Middle East are sometimes confronted with difficult working conditions including physical abuses like beatings, burns \& even rape". Migration especially to a new country, leads to stress and depression, as a result of alienation and the need to come to terms with new culture.

The other undesirable consequence of the strategy is associated with sending children out to earn income. Those children who have been sent out after school to generate income give more time for work than education. As a result, they may have poor performance in their education and face difficulties to pass to the next class. Others who dropped out of school and planned to continue at some point in the future will become below the appropriate grade in school than other students.

\section{CONCLUSION AND RECOMMENDATION}

The study found out that the relocation of people from inner city slum to the outskirt resulted in the upheaval of neighborhood social networks that prior to relocation played a pivotal role in supporting the people at times of adversity. However, relocation has enabled relocatees to get free of outsiders stigmatization. Especially, children, who were highly marginalized by the outsiders, have begun to feel safe after relocation. The study also found that relocated people have been more vulnerable to the urban economic shock. This is because, some quitted their jobs and others only generate low income. Moreover, lack of petty trade and the drastic food and petroleum price increase combined with social network upheaval are aggravating vulnerability of relocated people to the urban cash oriented life. It was also identified that relocation made relocated people to live in better and well planned environment and enabled children to find safe playing environment. As a result, health condition of relocatees is found to be impressive following their relocation.

The relocatees have employed various livelihood mechanisms against the adverse impacts of relocation. In this regard, it was found that relocatees' strategies have a strong income enhancement and expenditure reduction orientation. These have been achieved through increasing the quantity of labor in household, sending children to relatives and abroad, using second hand products, walking than using buses and adjusting consumption patterns. However, though such strategies have contributed to maintain relocatees 'livelihood, they also increase vulnerability and impoverishment instantly or in the long run. This study evidenced the adverse impacts of such strategies on individuals' productivity, health, social and educational assets. Facilitating training for relocatees to increase their skill level, and micro and small enterprises and credit services for them have a considerable role in curtailing vulnerability to urban economic context. This is important to keep them from life threatening livelihood strategies.

\section{REFERENCES}

1. Berhanu Zeleke. (2006). Impact of Urban Redevelopment on the Livelihoods of Displaced People in Addis Ababa: The case of Kasainchis. FSS 2-9, FSS, Addis Ababa.

2. Biruk Shiferaw. (2009). The Impact of Urban Development Projects on the Livelihoods of People Displaced from the Centre to the Periphery: The case of people Displaced from Kasainchis to CMC, GERGI \& MERI Areas, M.A Thesis in the department of Social Anthropology, Addis Ababa University (Unpublished).

3. Bloom, D. E., Canning, D. and Fink, G. (2008) Urbanization and the wealth of nations, Science, Vol. 319 , pp. 772 $-775$.

4. Brown, A. \& Lloyd-Jones, T (2002). Spatial planning, access and infrastructure in C Rakodi and T Lloyd-Jones (eds). Urban Livelihoods: A People-centred Approach to Reducing Poverty, 188-204. London: Earthscan.

5. Cohen, B (2005).Urbanization in Developing Countries: Current Trends, Future Projections, and Key Challenges for Sustainability, Technology in Society 28, Elsevier Ltd.

6. CSA (1998). The 1994 National Population and Housing census of Ethiopia, country report, Central Statistical Authority, Addis Ababa.

7. Elias Yitbarek (2008). Revisiting "Slums", Revealing Responses: Urban Upgrading in Tenant-Dominated InnerCity Settlement, Ethiopia. Doctoral Theses at NTNU 2008, Norwegian University of Science and Technology (NTNU), Trondheim.

8. Ephrem Tesema. (1998). Urban Adaptation and Survival Strategies: The case of Displaced Groups in the Arada Area Addis Ababa. M.A Thesis in the department of Social Anthropology, Addis Ababa University (Unpublished).

9. Farrington, J., Ramasut, T \& Walker, J (2002). Sustainable livelihoods approaches in urban areas : General Lessons, With Illustrations from Indian Cases. Overseas Development Institute Working Paper 162, Overseas Development Institute, London.

10. Gebre Yntiso (2008). Urban Development and Displacement in Addis Ababa: The Impact of Resettlement projects on Low-Income Households, EASSRR 53 -77, Organisation for Social Science Research in Eastern\& Southern Africa. 
11. Habtamu Atlaw (2014) .The impact of urban redevelopment-induced relocation on relocatees' livelihood assets and Activity in Addis Ababa: The case of people relocated Arat Kilo Area. Asian Journal of Humanities and social studies, volume 02-issue 01, pp 43-50.

12. Jespersen, E (1990). Household responses to the impact of the economic crisis on social services. In Reo, G. ( eds). Workshop on the effect of the structural Adjustment program in Malawi. Volume 2: Center for Social Research, University of Malawi, Zomba.

13. Mathewos Asfaw (2005). Current Housing Practice and Policy Issues in Addis Ababa,

14. Prepared for CRDA, Addis Ababa

15. Michalev, V. \& Westley, K (2002): The Use of Participatory Methods for Livelihood Assessment in Situations of Political Instability: A Case Study from Kosovo, ODI, London.

16. Moser, C (1998). The asset vulnerability framework: Reassessing urban poverty reduction strategies'. World Development 26 (2). 1-19.

17. Netsanent Teklehaymanot (2009). Dynamics of poverty in Addis Ababa, FSS Research Report no.3.

18. Potts, D (1997). Urban lives: Adapting new strategies and adapting rural links. In Rakodi, C. (eds.). The Urban Challenge in Africa : Growth and Management of its Large Cities, 447-494. UNU, Tokyo.

19. Rakodi, C and T Lloyd-Jones . (eds) .(2002). Urban Livelihoods: A People-centred Approach to Reducing Poverty, pages288. London : Earthscan.

20. Sommers, M (2010). Urban Youth in Africa: Environment and Urbanization. International Institute for Environment and Development, SAGE Publication.

21. Sufaira.C (2013). Socio Economic Conditions of Urban Slum Dwellers in Kannur Municipality IOSR Journal Of Humanities And Social Science (IOSR-JHSS), Volume 10, Issue 5. PP 12-24

22. UNHCS (United Nations Centres for Human Settlement). (1991). Evaluation of Relocation Experience. Nairobi, Kenya.

23. UN-HABITAT (2004). Relationship between Sustainable Development, Urbanization and Slums. "Think piece" prepared for the 12th session of the Commission for Sustainable Development, commissioned by the Norwegian Ministry of Environment, Unpublished.

24. United Nations Population Fund (UNFPA) (2007). State of the World Population 2007: Unleashing the Potential of Urban Growth, UNFPA, New York

25. UN- HABITAT (2007). Situation analysis of informal settlements in Addis Ababa, Human settlement program.

26. Yared, Amare (2010). Urban food insecurity and coping mechanisms: A case study of Lideta sub-city in Addis Ababa. FSS research report No.5. Addis Ababa.

Yenoineshet Meazash (2007). Integrated housing development programs for urban poverty alleviation and sustainable urbanization: The case of Addis Ababa, Housing and Sustainable urbanisation in developing countries: International Conference,

\section{AUTHOR'S BIOGRAPHY}

Habtamu Atlaw is a lecturer in department of Geography and Environmental Studies at Jigjiga University. He took B.Ed in Geography and Environmental Studies from Mekele University and MA in Urban Development and Urban Challenges in East Africa from Addis Ababa University. He served as a chairperson of Geography and Environmental Studies department for one year, in 2009. Currently, he serves as a research officer of Jigjiga University. 